\title{
Modelling and optimization of a local smart grid for an agro-industrial site
}

\author{
Enrico Fabrizio, ${ }^{1}$ Valeria Branciforti, ${ }^{2}$ Marco Filippi, ${ }^{2}$ Silvia Barbero, ${ }^{3}$ Giuseppe Tecco ${ }^{3}$ \\ ${ }^{1}$ University of Torino, Department of Agricultural, Forest and Food Sciences; ${ }^{2}$ Politecnico di \\ Torino, Department of Energy; ${ }^{3}$ Agrindustria s.n.c., Cuneo, Italy
}

\section{Introduction}

A smart grid is defined where different elements are interconnected between them and with the public utility grid. The development of smart grids is considered a strategic goal at both national and international levels and has been funded by many research programs. Within the BEE (Building Energy Ecosystems) project, funded by the Piedmont Region under the European POR FESR 2007-13 scheme, the creation of an electricity smart grid at a local level in a small agroindustry was done. This industry is one of the so-called prosumer, that is both a producer and a consumer of energy. The energy production is done by means of solar photovoltaic and biomass. In this local smart grid, the elements were subdivided in two main groups: loads (process machineries in the case study) and generators (PV and biomass in the case study). The loads may be further subdivided into permanent loads, mandatory loads and shiftable loads. The objective of the smart grid is the minimization of the exchanges between the local grid and the public utility grid. Even though no financial savings occur, this is important for the community grid. The problem is therefore to find the conditions that let the net exported energy going to zero at each time step, so arriving close to a self-sufficient system by modifying the shiftable loads. In a first phase of the study, the consumers were studied and, according to some characteristics of the machineries employed and the production requirements, grouped into production lines that can or not be switched off for intervals of time in order to compensate the smart grid fluctuations. The smart grid balancing may

Correspondence: Enrico Fabrizio, DISAFA, University of Torino, Via Leonardo da Vinci, 44, 10095 Grugliasco (T0), Italy.

Tel. +39.011.670.5525 - Fax: + 39.011.670.5516.

E-mail: enrico.fabrizio@unito.it

Keywords: sustainable factory, energy management, smart grid, production process optimization, energy saving

Contributions: the authors contributed equally.

Conflict of interest: the authors declare no potential conflict of interests. Funding: POR/FESR 2007-2014, Progetto BEE "Building Energy Ecosystems" del Polo di Innovazione Energie Rinnovabili della Regione Piemonte.

(C) Copyright E. Fabrizio et al., 2013

Licensee PAGEPress, Italy

Journal of Agricultural Engineering 2013; XLIV(s2):e111

doi:10.4081/jae.2013.s2.e111

This article is distributed under the terms of the Creative Commons Attribution Noncommercial License (by-nc 3.0) which permits any noncommercial use, distribution, and reproduction in any medium, provided the original author(s) and source are credited. be done on an instantaneous basis, or in a predictive way considering the future weather forecasts and the future production requirements. The demo site was equipped with measurement instrumentation, data acquisition tools and a user interface that may be used to visualize all the quantities that are measured but also to perform the actions suggested by the optimization strategy (start/stop machineries, organization of production, etc).

\section{Introduction}

The industrial sector is today responsible of about $20-50 \%$ (respectively countries with a long/new productive tradition) of final energy consumptions (Abdelaziz E.A., 2011; ENEA-UTEE, 2010). If considering the world industrial energy consumption over the next 25 years, it is projected to grow continuously, with an average increase of $1,4 \%$. per year from 2006 to 2030. Large margins of improvement still exist and also other positive effects would arrive about various related issues (environmental, social, economical) (Allwood J., 2011).

In industrial settlements it is more and more common to have some on-site generation or co-generation systems (Lazzarin R., 2010; Abdelaziz E.A., 2011). Furthermore industries can be part of energy initiatives at district level (with other industries or with urban centres) (Danestig M., 2011), thus leading to the emerging topic of "smart grids", that has been pointed out as a strategic goal in the future at both national and international levels. The approach that is followed is one of the most promising: the energy generation will be spread on the territory and the number of the so called prosumers, both producers and consumers of energy, will increase (Fabrizio E., 2012).

During the elaboration of innovative tools, aimed to obtain a better energy management, it is important to have a continuous interaction with the subjects who will benefit of these tools, collecting information about daily routine, priorities and possible sudden problems (Asian Productivity Organization , 2008). In this case the chance that the new management strategy will be put in practice is higher. Otherwise, if the provided management system is too difficult or not in accordance with company needs, the proposed innovations, though promising they are, will not be used and no advantages will arrive (Branciforti V., 2013). Concerning energy management, this means that every proposal, aimed to final energy or financial savings, should be flexible enough and should consider some free interventions by workers. In this way energy related goals will be easily achieved without compromising too much company activities. This will encourage people in using the new tools available for them, that would be otherwise immediately abandoned.

In case of on-site energy generation, the aim is to find the best matching between energy demand and supply under some constraints, in order to optimize the system management and exploit its internal potential. Because of self-production and direct consumption of energy, the total amount of energy derived by the external grid decreases and the balance between energy demand and production can arrive 
close to zero, if considering one month or all the year. For a more interesting result it is instead necessary to match energy demand and supply in shorter time periods, so going towards a self-sufficient settlement in almost each moment and thus minimizing the interaction with the external grid in both directions, feed-in and delivered energy.

In that sense the optimization helps in exploiting the system potential, by finding the best possible matching between energy demand and supply. The problem is quite difficult because it needs the definition of a complex system in which consumers and producers are different, are present in big number and each with particular needs.

An algorithm is defined in order to find the best management strategy of a system composed by consumers and producers of energy. The general mathematical formulation is useful to extend the approach to systems of different size and composed by various kind and number of subjects (a city with residential, office and industrial buildings that have energy demands and can also have local energy production, or a single firm with internal demands to be supplied and possible energy generators). An application of the latter case is presented in the case study. It is a small enterprise of the agro-food sector that hosts the demonstrative site of the project and that represents in itself an interesting example of internal exploitation of renewable energy sources and biomass.

An applied-research study was carried on by a partnership of academic and industrial subjects in 2011-2012, in order to investigate some new management strategies about electricity use at small district level. The optimization of energy use and the integration with production planning activities, were realized in an industrial demonstrative site located in North Italy. The project was co-financed by Piemonte Regional funds reserved to "research for companies". It was characterized by the involvement of academic, industrial and commercial partners, each interested in getting a more deep experience and knowledge about the smart-grids, a topic that has been pointed out as a strategic goal in the future at national and international level.

According to "20-20-20 scenarios" and to international regulations encouraging renewable energy use - and particularly the exploitation of biomass - the layout of actual energy network will change in future years. It will be probably characterized by many energy producers more and more spread on the territory, with an increasing number of prosumers. In recent years many projects are focusing on similar communities. The possible new situation would bear new challenges for the actual infrastructures capability, as the small storage capacity, the high transportation losses and the irregular demand and production profiles of different subjects belonging to the network. The grids should be improved in order to transmit energy in two directions and increasing the storage possibilities. One alternative solution to face all the present limits is the limitation of the storage units and an increased use of energy on site (Fabrizio E., 2012).

\section{The demo site}

\section{The buildings}

The demonstrative site is the small enterprise named Agrindustria, located in Piedmont region, North-west of Italy. The factory processes natural and vegetal materials that, by various working phases (cutting, drying, cooling, etc.), arrive to many final products, directly sent to the market (pellet) or sold to other companies of different sectors (makeup, monument conservation, animal feeds, automotive industry).

The industrial area is composed by 4 main buildings dedicated to different process phases, detached and divided by open areas, plus a civil building hosting the offices and a new structure built to cover the gasi- fier. The buildings features, their use and size are listed in Table 1. The buildings devoted to productive activities are composed of about 6.000 $\mathrm{m}^{2}$ of floor area and a corresponding total volume of $67.000 \mathrm{~m}^{3}$.

\section{The energy system}

Agrindustria can be considered a so called prosumer, that is a subject being both consumer and producer of energy. Thus the layout of the energy system characterizing the demo-site, both from the energy demand side and from the energy production side, contains many interesting elements that need to be properly considered in their mutual relationships.

The energy demand depends on the activities carried out that can be divided in "civil users" for the office building (ICT, printers and kitchen appliances), "industrial users" (productive machineries) and "building services", aimed at maintaining environmental conditions suitable for the different activities (lighting, environmental heating and cooling, safety systems, automatic gates and transportation systems). Among them, the industrial users represent of course the higher energy demand and are the focus of the present work.

A list of the energy demands and supplies is shown in Table 2. The following energy sources are here exploited:

- Electricity from the public grid;

- Natural gas from the public utility;

- Thermal energy, derived as waste of the syngas combustion process;

Table 1. Description of the buildings composing the industrial area used as demonstrative site.

$\begin{array}{lll}\text { Building } & \text { Use } & \text { Covered Volume } \\ \text { number } & \text { area }\left[\mathrm{m}^{2}\right] & {\left[\mathrm{m}^{3}\right]}\end{array}$

\begin{tabular}{lccc} 
Offices & Offices and kitchen & & \\
Building 1 & Raw material processing & 600 & 4500 \\
\hline Building 2 & Storage of raw material and packaged product & 1500 & 10000 \\
\hline Building 3 & Pellet production & 840 & 11350 \\
Building 4 & Mais derived production and mais storage & 3200 & 41500 \\
\hline Gasifier roof & Protection of co-generation plant & 234 & 0 \\
& Total & 6374 & 67350 \\
\hline${ }^{*}$ (closed or not by vertical walls on all sides); ${ }^{* *}$ (only completely enclosed spaces).
\end{tabular}

Table 2. List of the energy demands of the case study and of the different ways they are supplied.

\begin{tabular}{l} 
Energy demand \\
$\begin{array}{l}\text { Electricity } \\
\text { Electricity from the public grid (external supplier) } \\
\text { Electricity from PV panels (solar radiation on site) } \\
\text { Electricity from syngas engine (biomas in the gasifier on site) } \\
\text { Electricity from mini-wind generators (wind generators in chimneys) } \\
\text { Thermal energy from natural gas (external supplier) } \\
\begin{array}{l}\text { Thermal } \\
\text { energy }\end{array} \\
\begin{array}{l}\text { Thermal Energy for } \\
\text { Theoling purposes }\end{array}\end{array} \quad$ Electricity from the public grid (external supplier) \\
\hline
\end{tabular}


- Self-produced electricity from PV panels present on the buildings roofs;

- Self-produced electricity, deriving by a co-generation plant with internal combustion engine supplied by syngas.

Part of the energy is obtained by renewable energy sources, as:

- Solar radiation, to produce electricity through PV panels;

- Biomass, to produce syngas and consequently thermal energy and electricity;

- Wind-energy, through a small wind generator placed on steam chimneys

A schematic representation of the internal electricity distribution network is displayed in Figure 2, where the all elements listed above, are displayed together with their connections and locations. Different "traditional" energy source and renewable ones (biomass, solar energy, etc.) have been taken into account, because of already existing power plants. On the left side the 3 energy sources used within the factory are listed (electricity from the public grid, solar energy and biomass). On the right side, all final users are described with the name used by the internal staff and they are grouped in 5 clusters, depending on the building they are placed in (grey areas in Figure 2). In the central part of the scheme some converters are represented, as the PV panels and the gasifier. The lines connecting these elements and the arrows, show the way the electricity is distributed from the delivering point to all buildings, and from the arrival point of each building to machineries. All users are identified by their own name and a numeric code, useful to recognize them in all following elaborations. In Figure 3 some energy generators and some productive machineries of the demo site are shown.

\section{The energy demand characterization}

In order to characterize the energy demand (requested power and its profile during time), an inventory of the energy users was organized, using data deriving from the owner experience and needs, such as:

1. the list of all engines composing a productive machinery and of their power by target data; each productive line is considered as a single element with total power request equal to the sum of all parts composing it.

2. the average daily working hours of each machinery and the activation days per each week, according to the owner experience during last years.

3. the time that is necessary to conclude a complete working cycle and after which it is possible to stop the machinery.

4. the possibility to stop the activity of each machinery for a certain time - in order to modulate the total load - according to clients request and orders to be dispatched.

5. the location of each machinery in the building, in order to prepare possible monitoring activities for which machineries are connected to each electricity sub-station.

The following information was collected and organized in a table, related to each machinery:

- Numerical code (the same of the previous graphical scheme)

- Name commonly used within the company

- Performed process

- Building location

- Possibility to stop it and time needed to complete a working cycle

- Working hours per day and days of use per week

\section{- Nominal power}

Consumption data of the last 4 years were analyzed in order to know the whole system performance before the proposed management strategy. The average electricity consumption of the period 2008-2011 is about 3 GWh each year.

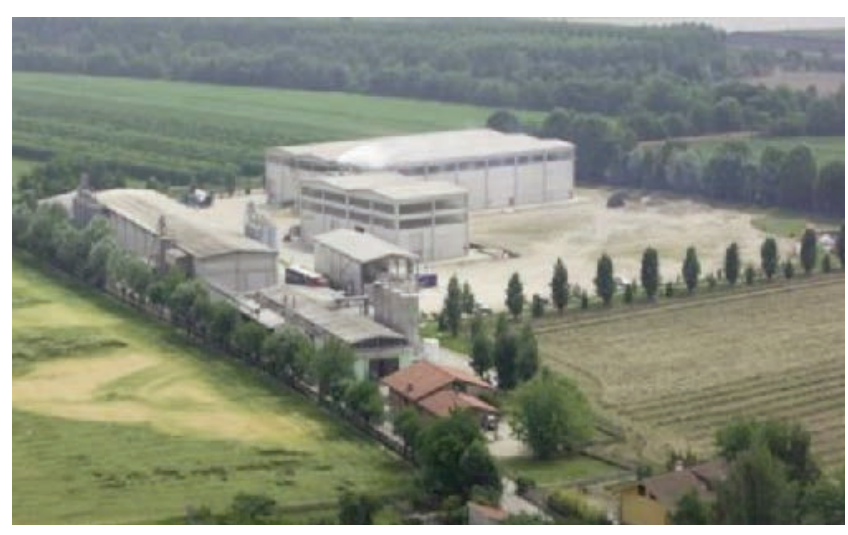

Figure 1. General view of the industrial area hosting the demo-site.

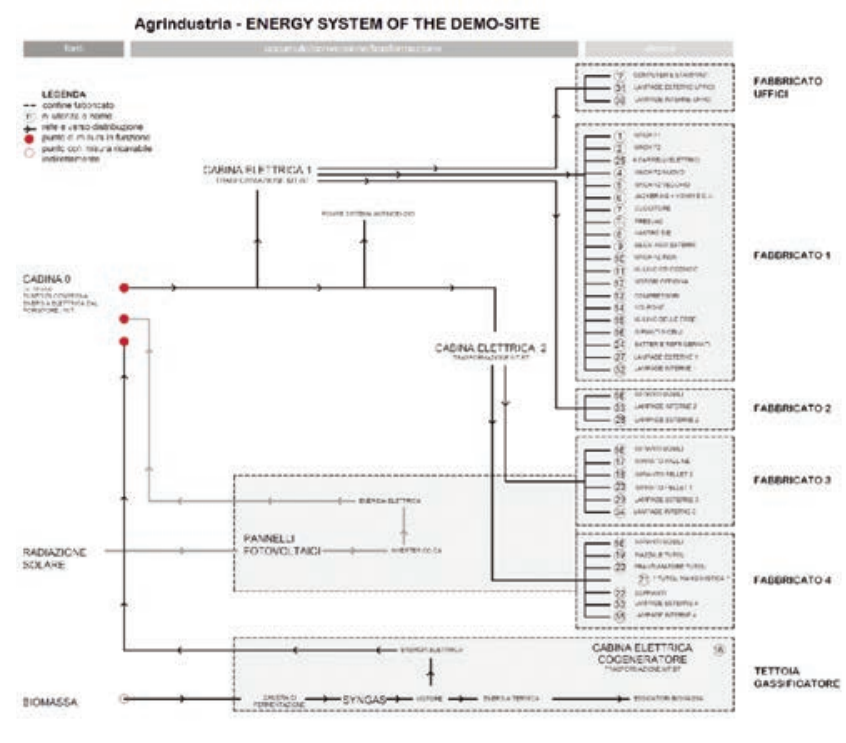

Figure 2. Schematics of the energy system demo-site.

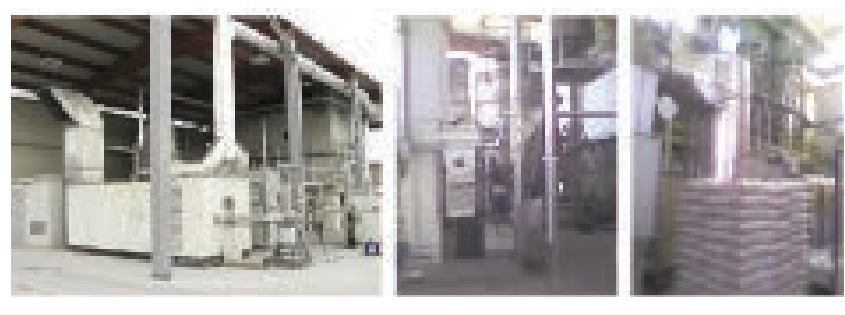

Figure 3. Some energy generators (left picture: gasifier) and loads (right pictures: process machineries) of the demo site. 


\section{The modelling framework}

\section{Smart grid modelling}

The model of a smart grid is reported in Figure 5. The elements can be divided in two main groups: the ones that use energy (loads) and are identified in red with $L$, and the ones that produce energy (generators) and are identified in green with $G$. The model is generalized as a system composed by $n$ loads and $m$ generators $\left(L_{n}\right.$ and $\left.G_{m}\right)$. The definition of the system boundaries is of great importance: the elements belonging to the local grid can be seen as an unicum: their relationship with the external grid is limited at just one connection point where a measure instrument is usually placed (identified as meter in the figure).

In that way it is possible to quantify:

- the total amount of energy produced by the generators and sent to the external grid $(F$, feed-in energy);

- the total amount of energy demanded by the loads, and provided by the external grid ( $D$, delivered energy);

- $\quad$ the net exported energy, $E$, defined as the net energy exported from the system to the external environment (Eq. 1):

$$
E\left(\Delta^{\prime}\right)=F(\Delta t)-D(\Delta t) \quad \forall \Delta^{\prime} \in T
$$

The aim of the smart grid management is to find the conditions that limit the import from the external grid and maximize the use of on-site generation. The net exported energy $(E)$ should tend to zero at each time step (thus arriving close to a self-sufficient system) or assume positive values (thus resulting in a positive energy system that produces more energy than the energy that is consumed, within a certain time period).

Each load is characterized by a profile of requested energy during time, called $l_{n}(t)$; similarly for each generator a profile or generated energy during time can be defined and it is called $g_{m}(t)$.

The energy requested by a generic user $L$ during the period $\Delta t$ is the integral of the function $l_{n}$ extended to the whole period $\Delta t$ :

$$
L_{n}=L_{n}(\Delta t)=\int^{+\Delta t} I_{n}(t) d t \quad[k W h]
$$

In the same way, the energy produced by a generator $G$ in the period $\Delta t$, can be expressed as:

$$
G_{m}=G_{m}(\Delta t)=\int^{+\Delta t} g_{w}(t) d t \quad[k W h]
$$

The total energy requested by all users of the local grid in the time period $\Delta t$, is called $L(\Delta t)$ and it is defined as the sum of all the requested energy quantities $L_{n}$ by all loads $L$ :
$L(\Delta t)=\sum_{n} L_{r}(\Delta t)$

Similarly,

$G(\Delta t)=\sum_{w} G_{n}(\Delta t)$

If the produced energy is not used locally and if no energy storages are present, the net exported energy, according to Eq. 1 can also be expressed as the difference between the total energy produced on site and the total demands,

$$
E(\Delta t)=G(\Delta t)-L(\Delta t)
$$

\section{Load clustering}

In order to define the optimization algorithm, it is necessary to establish some other features of the loads and the generators. An inventory of all energy end-users and generators was produced, characterizing each of them by specific parameters (power, activity period, energy consumed or product). Loads are clustered, with different priority and importance for the company, with a classification that was also used in the domestic sector (Vasquez F. I., 2011). They were subdivided into the following 3 categories (Figure 6):

- Permanent Loads $\left(L_{\text {perm }}\right)$ : those use or devices that work continuously over the time period $\Delta t$;

- Mandatory Loads $\left(L_{\text {mand }}\right)$ : those use that are not always in activity but that, for their function, must be activated immediately when requested;

- Shiftable Loads $\left(L_{\text {shift }}\right)$ : those use that are not continuously activated and that, because their function is not essential, can be switched off and satisfied later.

Shiftable loads can be considered as the only free variables of the system, the only elements that can be modified for optimization purposes, because they can be postponed if this is necessary to balance the smart-grid during a certain period $\Delta t$.

According to this loads classification, the previous total energy demand, $L(\Delta t)$, can be split into 3 terms, as expressed in Eq. 7 . The

\begin{tabular}{|c|c|c|c|c|c|c|c|c|c|c|}
\hline CODICE & & NORE & LAVOR ZIONE SVOLTA & 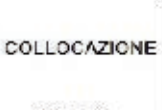 & $\begin{array}{c}\text { UINEA } \\
\text { SPEGNIBILE }\end{array}$ & $\begin{array}{c}\text { TEMPO } \\
\text { COMPLETANENTO } \\
\text { DI UN CICLO DI } \\
\text { LANOR } n Z I O N E \\
{[\mathrm{~m} n]}\end{array}$ & $\begin{array}{l}\text { OFE ATTVITA } \\
\text { GIORNALIERE } \\
\text { [h/g] }\end{array}$ & $\begin{array}{c}\text { GIORNII } \\
\text { ATTIVITA } \\
\text { SETTINANAU } \\
\text { [g/3cttimena] }\end{array}$ & $\begin{array}{c}\text { OFEIANNC } \\
\text { DI ATTIVITA } \\
\text { STIMATE } \\
\text { [W/aCno] }\end{array}$ & $\begin{array}{c}\text { PUTEN } \angle A \\
\text { INSTALLATA } \\
{[\mathrm{kW}]}\end{array}$ \\
\hline \multirow[t]{2}{*}{1} & \multirow[t]{2}{*}{$\mathrm{MACH} F 1$} & & \multirow[t]{2}{*}{ 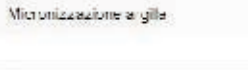 } & \multirow[t]{2}{*}{1} & $s r$ & 10 & 8 & $z$ & 2000 & 25 \\
\hline & & & & & & \multicolumn{3}{|c|}{ TC'ONZIANKOCALOO_ATC } & & \\
\hline \multirow[t]{2}{*}{2} & \multirow[t]{2}{*}{$\mathrm{MACH} F 2$} & & \multirow[t]{2}{*}{ neacoctnac argile } & \multirow[t]{2}{*}{7} & $\leqq r$ & \multirow[t]{2}{*}{3} & 6 & 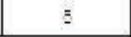 & 1600 & 6 \\
\hline & & & & & & & TC- CFEta & WhOCALCO_ATE & & \\
\hline \multirow[t]{2}{*}{3} & \multirow[t]{2}{*}{ VORTICE } & \multirow[t]{2}{*}{ sersante tate } & \multirow{2}{*}{ 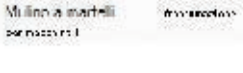 } & \multirow[t]{2}{*}{ ? } & \multirow[t]{2}{*}{ - } & \multirow[t]{2}{*}{$\cdot$} & 0 & 8 & 0 & \multirow[t]{2}{*}{0} \\
\hline & & & & & & & \multicolumn{2}{|c|}{$T^{-} T E=A \Delta V \cap \cap A M M T F$} & & \\
\hline 4 & \multicolumn{2}{|c|}{ MAI:II 2 N(KIVI) } & 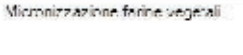 & ? & N:I & s & 24 & 4 & 41131 & 42 \\
\hline
\end{tabular}
total number of permanent loads is $a$, of mandatory loads is $b$ and of shiftable loads is $c$, being $n=a+b+c$.

$$
L(\Delta t)=\sum_{n} L_{n}(\Delta t)=\sum L_{p \times s t a t}(\Delta t)+
$$

Figure 4. Extract of the energy users inventory. 
$\sum_{b} L_{\text {astid } b}(\Delta t)+\sum L_{\text {shgi, }}(\Delta t)$

\section{Instant optimization}

The objective function of the optimization problem is expressed as:

$$
f(E(\Delta t))=0 \quad \forall(\Delta i) \in T
$$

and searches those values able to determine a net exported energy $E(\Delta t)$ close to zero, for each time period $\Delta t$.

According to the definition of $E(\Delta t)$ given in Eq. 6 and substituting the value of $L$ with the loads classification provided in Eq. 7, the net exported energy going from the system to the external grid, can be expressed by the Eq. 9:

$$
\begin{aligned}
& E(\Delta t)=G(\Delta t)-L(\Delta t)=\sum_{w} G_{s t}(\Delta t)-\sum_{p} L_{p m, s}(\Delta t)- \\
& \sum L_{\text {avsad } b}(\Delta t)-\sum L_{\text {shgi }}(\Delta t)
\end{aligned}
$$

The decision variables of the optimization problem are the shiftable loads. The Boolean parameter $\pi$ is introduced in the model, associated to each load to indicate its activation in a given period of time ( 0 indicates the off mode and 1 indicates the on mode).

$$
\pi=[0,1]
$$

Associating a parameter $\pi$ to each load, the objective function can be written as:

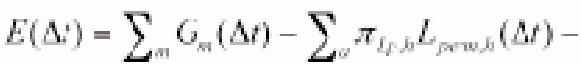

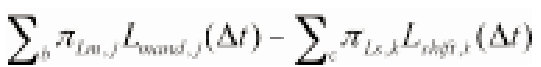

The solution of the optimization problem (expressed by Eq. 12) is a group of $n$ parameters $\pi$, one for each load: this combination of various switching on and off modes of the loads satisfies the balance aim, as expressed in Eq. 6 and according to the constraints expressed in Eqs. 13 and 14.

$$
\begin{aligned}
& \{\pi, \ldots, \ldots, \tau\}:(E(\Delta l)) \rightarrow 0 \quad \forall \Delta i \in T \\
& \pi_{p, i}=1 \quad \forall i \\
& \pi_{w, j}=1 \quad \forall j
\end{aligned}
$$

Each load with $\pi$ equal to zero should be switched off during the considered time period, while each load with $\pi$ equal to 1 can be activated during the same time period. This approach is similar to the optimization performed for multi-energy systems in the works (Fabrizio et al., 2009; Fabrizio et al. 2010; Fabrizio, 2011).

\section{Predictive optimization}

If the instant optimization is repeated for many successive time steps, it is possible to schedule an all day, week or month, thus planning activities in the best way to match both energy optimization goals and production needs. The considered time period is defined in Eq. 15 as $T$ and it includes all time steps $\Delta t_{i}$.

$$
T=\sum_{i=1}^{j} \Delta t_{i}
$$

The mathematical expression of the objective function is Eq. 16. It is similar to the instant optimization but with some differences. It is extended to many time periods and the optimization is done on the absolute value of the net exported energy, in order to avoid compensations between positive and negative values of $E(\Delta t)$ in different $\Delta t$ intervals. $f\left(\sum_{i=1}^{p} \mid E\left(\Delta t_{i}\right)\right) \rightarrow 0 \quad \forall \Delta t \in T$

The loads classification and the meaning of the parameter $\pi$ are the same of the instant optimization.

The problem solution is the set of parameters $\pi$, referred to the shiftable loads, as expressed in Eq. 17. Those values compose a matrix with $q$ rows, corresponding to the included time periods, and $k$ columns, corresponding to all considered shiftable loads, as shown in Figure 7.

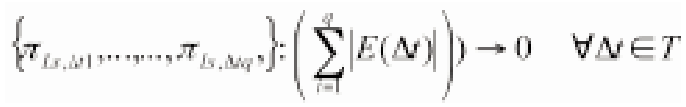

$\sum_{i=1}^{c} \pi_{L, t}=x \quad \forall L_{x, k}$

In order to meet the daily company needs, that are independent from the energy issues, a further possibility is provided within the proposed optimization logic. The person or the staff, who are in charge for the production management, can express the total number of activation that each shiftable load must complete in the time period $T$ : these

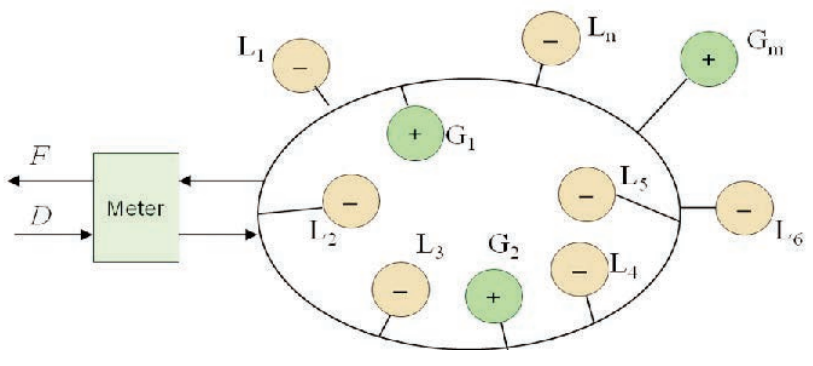

Figure 5. Scheme representing the virtual grid.

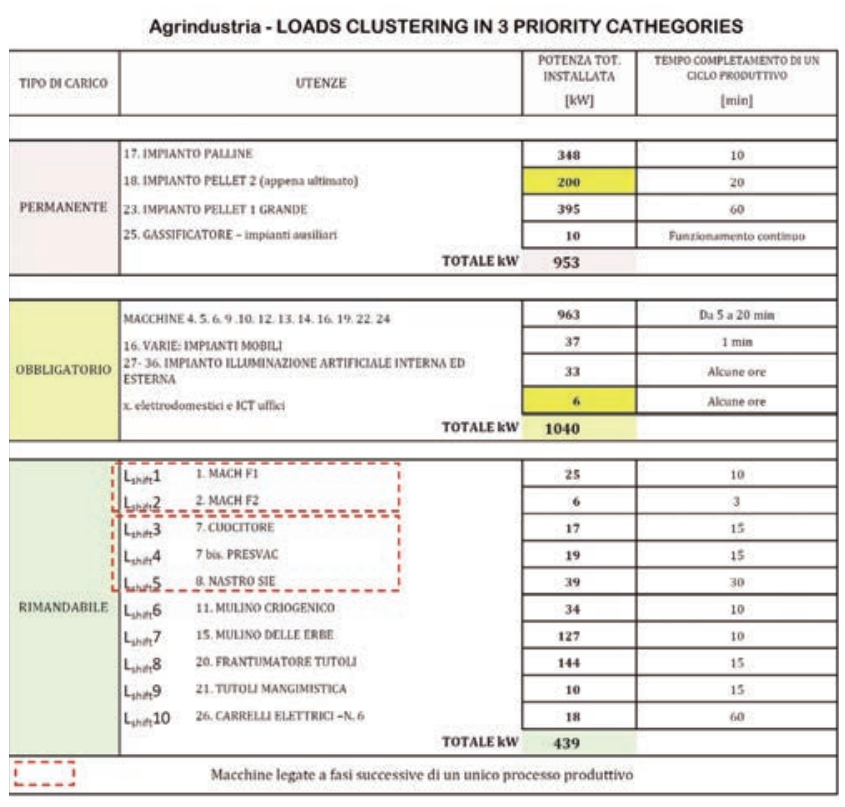

Figure 6. The Loads grouped in the 3 priority categories. 
loads, because identified as shiftable, will be considered by the algorithm calculations as machineries whose activation can be planned in the most suitable moment (according to energy matching goals) but with a minimum required number of working cycles that must be completed over the considered period (according to the company orders and needs).

The number of total desired cycles for each shiftable load, is easily provided by the staff and it originates a new constraint for the algorithm during the calculation towards the best solution, represented by Eq. 18. The result is a plan of activities for the period $T$, shown by a user interface, where a combination of various switching on and off of shiftable loads takes the whole system closer to the balance, satisfying both the energy matching goals and the needs of the company about the use of machineries.

The on-off functioning can also be automated but this option needs to be carefully evaluated. Preferably only the information on the best layout of activities is given to the users, that can decide weather or not following the indications.

An intelligent control unit was programmed according to these instructions. In this device some data also converge: they are real time data from measurement tools on the field, weather forecast, estimation based on previous days and constraints decided by the user for that period (urgent orders, priority of some activities, etc.). The intelligent central unit shows information through an interface. Furthermore with very easy calculations it is possible to obtain consumption and production profiles and some indicators of load-matching or grid-interaction, to easily communicate how the system is performing about the desired results.

\section{Smart grid indicators}

Some indicators were calculated to analyze the performance of the overall system and the results obtained thanks to the proposed management strategy. They are one load matching indicator and two grid interaction indicators, thus providing some useful information about the reaching of the project goals, the effectiveness of the proposed strategy and the relationship between the system and the external grid.

- Load cover factor over period $T(\gamma(\Delta t))$ : it is the ratio between the smallest between the total generated power and the total requested power, over the total requested power. It expresses in percentage which is the part of the total load that was supplied by on site generated energy. In the most successful case, it will be equal to $100 \%$, thus meaning that the all demand was supplied by on site generation.

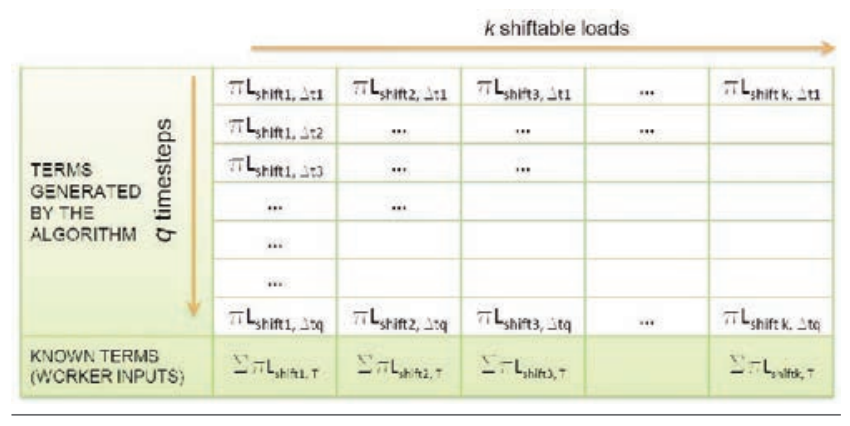

Figure 7. Matrix resulting from the predictive optimization algorithm.

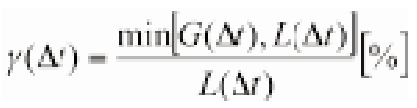

- Relative grid interaction amplitude $\left(A_{g r}\right)$ : it is the difference between the maximum and the minimum values of net exported energy registered over period $T$, both normalized by the total design load of the system.

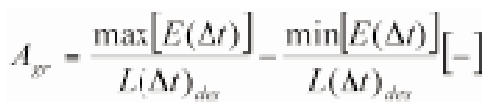

- $\quad$ No grid interaction probability $\left(P_{E \approx 0}\right)$ : it represents the probability that the system is working in autonomy of the grid, by using on site generation to cover the entire load. It is the number of time steps characterized by a value of net exported energy almost equal to zero, over the period $T$, this ration being expressed in percentage.

$P_{E \sim 0}=\frac{\operatorname{time}_{|E(\Lambda)|=0,00 \mid}[\%]}{T}[\%$

\section{Application}

The described logic was applied to the demo-site in an example of predictive optimization. The local grid was defined, to be programmed along a period $T$ composed by 8 time intervals $\Delta t$, and having the following features:

- 3 generators producing the following design power: $G_{l}=523 \mathrm{~kW}$ (PV panels on building 3 and 4); $G_{2}=196 \mathrm{~kW}$ (PV panels on building 1 and 2); $G_{3}=200 \mathrm{~kW}$ (gasifier); the total produced power is $919 \mathrm{~kW}$, with a time variable production schedule as shown in Figure 8.

- Permanent and mandatory loads, with following features: $\Sigma L_{\text {perm }}=$ $953 \mathrm{~kW}, \Sigma L_{\text {mand }}=1040 \mathrm{~kW}$ or less, depending on the considered interval (for example because of daily hours of offices activity or evening and night time with light activation). The time schedule of the power requested by these loads is represented in Figure 9 .

- Shiftable loads, with the following features: $L_{\text {shift } 1+2}=31 \mathrm{~kW}$, Lshift

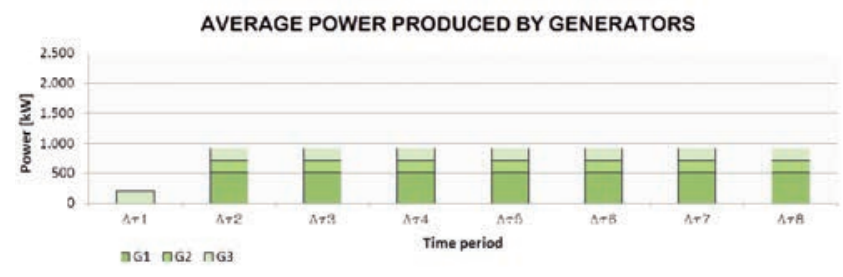

Figure 8. Time schedule of the power requested by permanent and mandatory loads over.

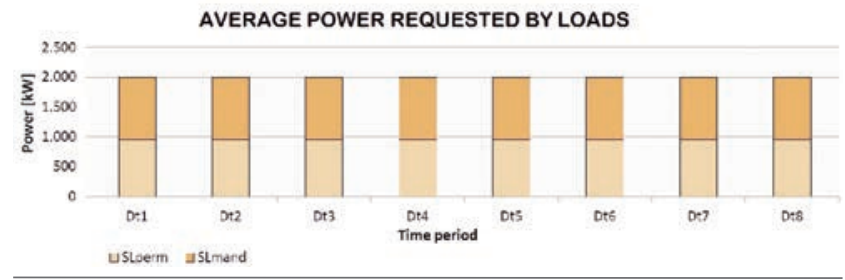

Figure 9. Time schedule of the power produced by generators in the 8 time intervals of the period $T$. 
$3+4+5=75 \mathrm{~kW}, L_{\text {shift } 6}=34 \mathrm{~kW}, L_{\text {shift } 7}=127 \mathrm{~kW}, L_{\text {shift } 8}=144 \mathrm{~kW}, L_{\text {shift } 9}$ $=10 \mathrm{~kW}, L_{\text {shift } 10}=18 \mathrm{~kW}$.

For each shiftable load a number of necessary activation periods during was defined. The information is provided as total amount of activations for the 7 identified shiftable loads: $\Sigma \pi L_{\text {shift } 1+2}=2$, $\Sigma \pi L_{\text {shift } 3+4+5}=1, \Sigma \pi_{L_{\text {shift } 6}}=3, \Sigma \pi_{\text {Lshift } 7}=1, \Sigma \pi L_{\text {shift } 8}=1 \Sigma \pi_{\text {Lshift } 9}=2$ and $\Sigma \pi L_{\text {shift } 10}=1$, that respectively means that the first group of machineries must be activated twice during the period $T$, the second only once, the third 3 times and so on.

The constraints are expressed as follows:

$\begin{array}{llll}\pi L_{n}=[0,1] & \pi L_{\text {perm }}=1 & \pi L_{\text {mand }}=1 \text { or } 0 & \\ \Sigma \pi L_{\text {shift } 1+2}=2 ; & \sum \pi L_{\text {shift } 3+4+5}=1 ; & \sum \pi L_{\text {shift } 6}=3 ; & \Sigma \pi L_{\text {shift } 7}=1 ; \\ \Sigma \pi L_{\text {shift } 8}=1 & \sum \pi L_{\text {shift } 9}=2 ; & \sum \pi L_{\text {shift 10 }}=1 & \end{array}$

The group of values that, for the given constraints, satisfy Eq. (17) are represented in a matrix in Figure 10. Each column represents one of the 7 shiftable loads and each row represents one of the 8 time intervals $\Delta t$. The energy produced by generators is not enough to supply permanent and mandatory loads. The situation changes after the time period $\Delta t_{l}$, when two more generators start to work. This change is shown in the first chart of Figure 11. It is in that phase, since the $2^{\text {nd }}$ time interval, that the problem solution indicates to place the shiftable loads, distributing them in order to arrive closer to the system balance and to satisfy the requested number of working process, expressed as constraint.

The second chart of Figure 11 shows the time intervals in which the energy demand is higher than the energy supply, and the opposite situation. The third chart of Figure 11 represents the value of net exported energy $E(t)$. The negative values highlight a scarcity of self-produced energy in comparison to the energy demand of the same moment, thus imposing to use energy coming from the external grid. This chart is also useful to quantify the distance of the value assumed by $E(\Delta t)$ from the ideal situation of perfect supply-demand matching.

For the present example, the values of the 3 indicators previously described, are shown in Figure 12. Less than a half of the total request was supplied by the generators, with the Load cover factor over period $T \gamma(\Delta t)$ corresponding to $40 \%$. The interaction with the external grid was continuous, because at no time step the energy generated on-site was sufficient to totally supply the demands: for this reason the No grid interaction probability $\left(P_{E \approx 0}\right)$ is equal to zero. Nevertheless this interaction was characterized by a quite flat profile, and the quantity requested to the external grid was quite constant during the all period, except for the first time step, as shown in the last chart of Figure 11: the Relative grid interaction amplitude $\left(A_{g r}\right)$ was in this case 0,3 .

\section{Conclusions}

The optimization algorithm was developed for this case study but the mathematical formulation allows extending it in time and space and to almost any other case study, in terms of different size and also including different final users, dwellings, etc. Moreover it is possible to pursue the optimization of small single smart-grids and then setting a bigger system in order to establish exchanges of energy between them, with a similar optimized logic. In other case studies the results could be more evident according to the energy produces by generators and the number and features of the shiftable loads (that in the presented case study correspond to $1 / 5$ of the total loads in terms of power).

The intelligent central unit shows information through an interface. Furthermore with very easy calculations it is possible to obtain consumption and production profiles and some indicators of load-matching or grid-interaction, to easily communicate how the system is performing about the desired results.

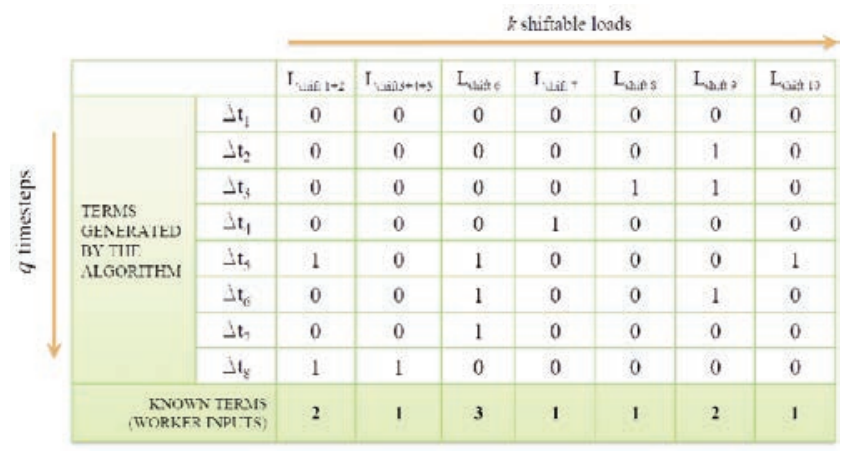

Figure 10. The matrix resulting from predictive optimization.
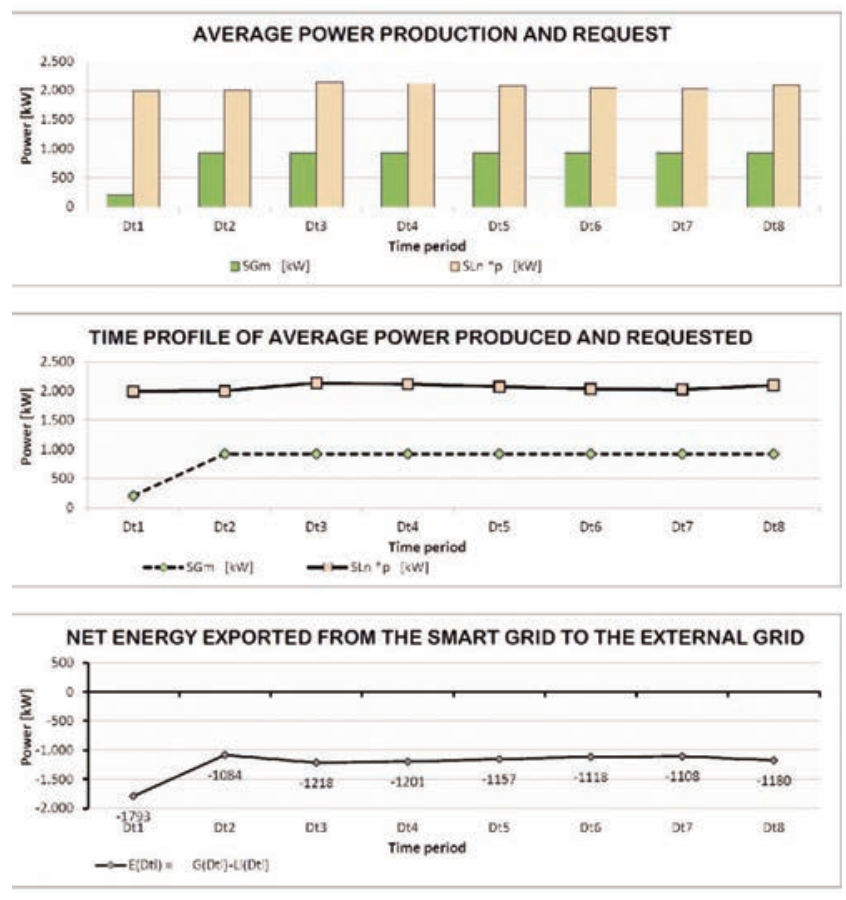

Figure 11. Supply and demand and Net Exported Energy over period T.

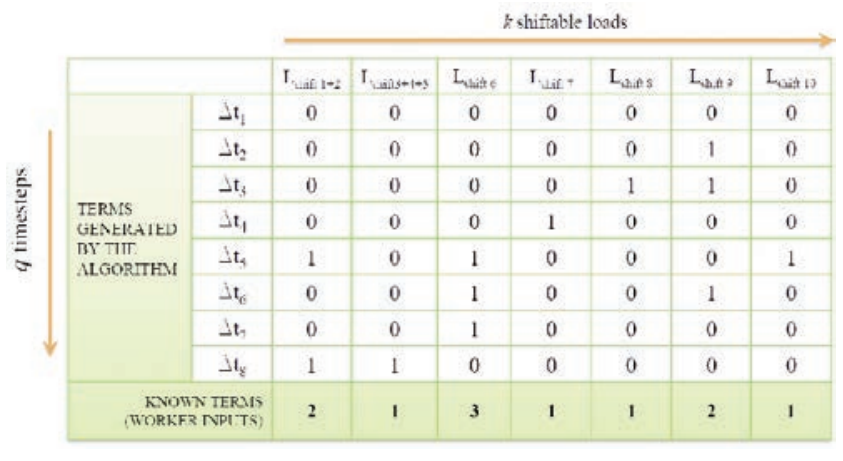

Figure 12. Performance indicators of he smart grid. 
It is important to arrive to the matching between demand and supply not only for the obtainable financial advantages (place some loads in the hours of energy surplus, thus profiting of hourly fees) but also because, through a reduced interaction with the external grid, the quantity that is transmitted, and the related distribution losses, decrease.

A deep knowledge of the consumption of factories is among the interests of many actors of the energy supply chain. Because industries are the final clients of this chain, public utilities usually offer specific fees and discounts for those clients who implement some tools to have a more predictable energy profile (monitoring plans for example): in that way the energy trader limits the risk deriving from wrong prediction about the quantity of booked and bought energy quantity, and the consequent penalties for not correct predictions. Moreover the database obtainable with a monitoring activity, with past years data, can be a starting point for a continuous monitoring plan, in order to activate a virtuous process of improvement and control.

Concerning energy management, every proposal, aimed to final energy or financial savings, should be flexible enough and should consider some free interventions by workers. In this way energy related goals will be easily achieved without compromising too much company activities. This will encourage people in using the new tools available for them, that would be otherwise immediately abandoned.

\section{Nomenclature}

a number of permanent loads

$b \quad$ number of permanen loads

$c \quad$ number of permanen loads

$i \quad$ generic time step $\mathrm{t}$

$h \quad$ number of permanent loads

$j \quad$ number of mandatory loads

$k \quad$ number of shiftable loads

$n \quad$ number of loads

$m \quad$ number of generators

$\pi$, perm permanent

$m$, mand mandatory

shift shiftable

$q \quad$ number of time step $t$ within period $T$

$D \quad$ delivered energy

$F \quad$ feed-in energy

$E \quad$ net exported energy

$L \quad$ load

$G$ generator

$\varnothing t \quad$ time step

$T \quad$ total time period

$\gamma \quad$ Load cover factor over period T

$A_{g r} \quad$ Relative grid interaction amplitude

$P_{E \approx 0} \quad$ No grid interaction probability

\section{References}

Abdelaziz E.A., Mekhilef S. 2011. A review on energy saving strategies in industrial sector. Renewable and Sustainable Energy Reviews , 15 (1), 150-168.

Abdelaziz E.A., Mekhilef S., Saidur R. 2011. A review on solar energy use in industries. Renewable and Sustainable Energy Reviews , 15, 1777-1790.

Allwood J., Cullen J. 2011. Sustainable Materials - with Both Eyes Open: Future Buildings, Vehicles, Products and Equipment - Made Efficiently and Made with Less New Material. Cambridge, UK, UIT Cambridge.

Asian Productivity Organization . 2008. Working manual on energy auditing in industries - Results of the workshop "Energy efficiency and green productivity". New Delhi, India,: APO and National Productivity Council (NPC).

Branciforti V. 2013. Rational use of energy and materials in industrial areas. Torino: Politecnico di Torino.

Cimren E., Fiksel J., Posner M.E., Sikdar K. 2011. Material Flow Optimization in By-Product Synergy Networks. Journal of Industrial Ecology, 15 (2), 315-33.

Danestig M., Trygg L. Difs K. 2011. Increased use of district heating in industrial processes - Impacts on heat load duration. Energy Procedia IACEED2010, 1584-1588.

ENEA- UTEE Unità Tecnica Efficienza Energetica. 2010. "Rapporto Enea Energia e Ambiente". Roma.

Fabrizio E. 2011. Feasibility of polygeneration in energy supply systems for health-care facilities under the Italian climate and boundary conditions. Energy for Sustainable Development, 15(1), 92-103.

Fabrizio E., Corrado V., Filippi M. 2010. A model to design and optimize multi-energy systems in buildings at the design concept stage. Renewable Energy, 35(3), 644-655.

Fabrizio E., Filippi M., Branciforti V. 2012. Deliverable Progetto Regionale, "BEE Building Energy Ecosystem" . Torino: Politecnico di Torino, Dipartimento Energia, Torino.

Fabrizio E., Filippi M., Virgone J. 2009. An hourly modelling framework for the assessment of energy sources exploitation and energy converters selection and sizing in buildings. Energy and Buildings, 41(10), 1037-1050.

Lazzarin R., 2010. Recupero energetico nei processi industriali, Convegno AICARR "Riduzione dei fabbisogni, recupero di efficienza e fonti rinnovabili per il risparmio energetico nel settore industriale Padova."

Vasquez F. I., K. W. 2011. Electricity load management in smart home control. Sydney: 12th Conference of Building Performance Simulation Association. 